Research Paper

\title{
Low-Density Lipoprotein Receptor-Related Protein 6 (LRP6) rs 10845498 Polymorphism Is Associated with a Decreased Risk of Non-Small Cell Lung Cancer
}

\author{
Dehou Deng ${ }^{1,2}$, Yongjun Zhang ${ }^{1 凶}$, Wenglong Bao ${ }^{1}$, Xiangming Kong ${ }^{1}$ \\ 1. Department of Integrated Traditional Chinese and Western Medicine, Zhejiang Cancer Hospital, Hangzhou 310022, China; \\ 2. The First Affiliated Hospital, Zhejiang Chinese Medical University, Hangzhou 310035, China.
}

$\triangle$ Corresponding author: Yongjun Zhang, Department of Integrated Traditional Chinese and Western Medicine, Zhejiang Cancer Hospital, 38 Banshan Road, Hangzhou 310022, China; Tel.: +86-571-8812 2372; Fax: +86-571-8646 1861; E-mail: zhangyj@zjcc.org.cn.

(c) Ivyspring International Publisher. This is an open-access article distributed under the terms of the Creative Commons License (http://creativecommons.org/ licenses/by-nc-nd/3.0/). Reproduction is permitted for personal, noncommercial use, provided that the article is in whole, unmodified, and properly cited.

Received: 2014.02.17; Accepted: 2014.04.04; Published: 2014.05.02

\begin{abstract}
Objectives: Low-density lipoprotein receptor-related protein 6 (LRP6) modulates Wnt signaling transduction. Altered LRP6 expression leads to abnormal Wnt protein activation, cell proliferation and tumorigenesis. This study investigated the association between LRP6 single-nucleotide polymorphisms (SNPs) and non-small-cell lung cancer (NSCLC) in a Chinese population. Methods: A total of 500 NSCLC patients and 500 healthy controls were recruited for assessment of four LRP6 SNPs using the SEQUENOM MassARRAY matrix-assisted laser desorption ionization-time of flight mass spectrometry. The association between genotype and NSCLC risk was evaluated by computing the odds ratio $(\mathrm{OR})$ and $95 \%$ confidence interval $(\mathrm{Cl})$ with multivariate unconditional logistic regression analyses. Results: The frequency of the LRP6 rs 10845498 genotype was $60.9 \%$ $(A / A), 35.5 \%(A G)$ and $3.6 \%(G G)$ in patients with lung squamous cell carcinoma (SCC) and $69.2 \%$ $(\mathrm{A} / \mathrm{A}), 27.2 \%(\mathrm{~A} / \mathrm{G})$ and $3.6 \%(\mathrm{GG})$ in controls. Logistic regression analysis revealed that the LRP6 $\mathrm{rs} 10845498 \mathrm{~A} / \mathrm{A}$ major allele was associated with a reduced risk in developing lung SCC $(\mathrm{OR}=$ 0.69; $95 \% \mathrm{Cl}, 0.48-\mathrm{I} .00 ; \mathrm{P}=0.04$ ), and tobacco smokers had a $2.2 \mathrm{I}$ fold greater risk in developing SCC than nonsmokers $(P<0.01,95 \% \mathrm{Cl}, 1.72-2.85)$, and tobacco smokers who carried an " $A$ " allele (AA+AG) in rs6488507 had a 2.34-fold greater risk in developing NSCLC than other patients $(p<0.01,95 \% \mathrm{Cl}, 1.74-3.13)$. Conclusions: The LRP6 rs 10845498 SNP is associated with a reduced risk of lung SCC, while tobacco smoke increases the risk. LRP6 rs6488507 polymorphism synergistically increased the risk of NSCLC in tobacco smokers. Further studies are needed to elucidate the functional impact of LRP6 expression and activity in NSCLC.
\end{abstract}

Key words: Non-small cell lung cancer, genetic susceptibility, low-density lipoprotein receptor-related protein 6 , single nucleotide polymorphism.

\section{Introduction}

Lung cancer contributes significantly to cancer-related mortality and is a major public health burden in the world [1]. In China alone, the incidence and mortality associated with lung cancer are estimated to be 0.7 and 0.6 million cases, respectively [2]. To date, most lung cancer patients are diagnosed at an advanced stage with a 5-year survival rate of approximately $15 \%$, whereas the 5 -year survival rate of early stage lung cancer patients is $30-40 \%$. Thus, early detection and effective treatment could markedly improve patient survival [3]. Pathologically, genetic and environmental interactions play a key role in the development of lung cancer [4]. However, these interactions are dependent of genetic variations or single nucleotide polymorphisms (SNPs). Therefore, identifying specific SNPs associated with an increased 
risk of developing lung cancer could reduce lung cancer incidence.

The proto-oncogene Wnt- 1 belongs to the WNT family of structurally related genes that encode secreted signaling proteins. Functionally, these proteins have been implicated in both tumorigenesis and embryonic development, including cell fate and patterning [5-11]. The Wnt co-receptor, low-density lipoprotein receptor-related protein 6 (LRP6), plays a dominant role in Wnt signal transduction [12]. LRP6, a member of the LRP superfamily, is required for activation of the canonical Wnt signaling pathway. Structurally, human LRP6 protein has a large extracellular domain containing four $\beta$-propeller-plus EGF repeats, which are essential for binding to Wnt, various ligands and antagonists, and three LDLR-A repeats [13-14]. Aberrant LRP6 expression alters Wnt ligand binding and receptor activation, and extracellular antagonists are associated with stem cell self-renewal and differentiation as well as cancer development and progression [15]. Specifically, LRP6 protein binding to the Frizzled family member, leads to the activation of the Wnt pathway [16] and the subsequent stabilization and nuclear translocation of $\beta$-catenin [17]. Pharmacological inhibition of the LRP6 Wnt-binding domains leads to the suppression of the Wnt pathway and its downstream gene regulatory mechanisms [18]. In this study, we hypothesized that LRP6 polymorphisms could play a role in the susceptibility of non-small cell lung cancer (NSCLC). Specifically, we assessed four different LRP6 SNPs in a case and control study to determine their association with the risk of developing NSCLC.

\section{Patients and Methods}

\section{Study population}

In this study, we recruited 500 NSCLC patients and 500 unrelated age-matched healthy controls from The Zhejiang Cancer Hospital, Hangzhou, China between March, 2011 and April, 2012. All subjects were of Han origin and lived roughly within the same geographic region (Zhejiang Province, China). Patients with a prior history of primary cancer, other than lung cancer, were excluded from this study. To avoid any probable interference from overlapping genes, the controls did not have any lung-related diseases. A tobacco smoker was defined as one who had smoked more than ten packs of tobacco in their life time, and a current or former smoker was defined as a smoker who was still smoking in the current year or in a year before participation of this study [20]. This study was approved by the ethics committee of Zhejiang Cancer Hospital. All subjects included in this study provided informed consent before participation.

\section{SNPs selection and genotyping}

Four LRP6 SNPs, with a pairwise $\mathrm{r}^{2} \geq 0.8$ and minor allele frequency (MAF) $\geq 0.15$, were selected by searching the SNP Browser (version 3.5) and the Tagger program implemented in Haploview version 4.1 (http://www.broad.mit.edu/mpg/haploview).

We extracted genomic DNA from whole blood using the AxyPrep Blood Genomic DNA Miniprep kit (Axygen Biosciences, Union City, CA). The four LRP6 SNPs of interest were then genotyped using the SEQUENOM MassARRAY matrix-assisted laser desorption ionization-time of flight mass spectrometry platform (Sequenom, San Diego, CA). PCR primers and single base extension primers were designed using Assay Designer's software version 3.0 (Sequenom) and synthesized by Sangon Biotech (Shanghai, China) (Table 1).

Table I. PCR primers and extension used in genotyping of LRP6 SNPs.

\begin{tabular}{lll}
\hline SNP & Primers & Sequences \\
\hline Rs10845498 & 1 & ACGTTGGATGGAGAGGACTGTTAAAGCTGG \\
& 2 & ACGTTGGATGTGTGTGGTTAATGTGGGAGG \\
Rs2075241 & Extension & CCCTGGAGAGTAGGGGAGAGAGAG \\
& 1 & ACGTTGGATGCACAGGCTGCAAGATATTGG \\
Rs6488507 & ACGTTGGATGTGACCCACATGAGTCATTTC \\
& 1 & GAACTGAGTCATTTCTGTTGAATTTTCT \\
2 & ACGTTGGATGGTTAATAAGTAATCTGTGGG \\
Rs7136900 & Extension & ACGTTGGATGCAAGGATTCAAAAACCACTG \\
& 1 & AAAGGATATTTACACCATTTCA \\
& 2 & ACGTTGGATGACAGTTGTATGCCACTGTGC \\
& Extension & ACGTTGGATGAAGCTTACAGCCTAGTTTGG \\
\hline
\end{tabular}




\section{Statistical analysis}

All statistical analyses were performed using SPSS 13.0 for Windows (SPSS Inc., Chicago, IL). Hardy-Weinberg equilibrium (HWE) was carried out between cases and control for all SNPs using the $\chi^{2}$ test. A $P<0.001$ was considered discrepant. The $\chi^{2}$ test was also used to assess the frequencies of the selected alleles and genotypes. The association between SNPs and NSCLC risk and the link between tobacco smoke and NSCLC risk were evaluated by computing the odds ratio (OR) and 95\% confidence interval (CI) with multivariate unconditional logistic regression analyses. A two-sided $\mathrm{P}<0.05$ was considered statistically significant.

\section{Results}

\section{Clinical characteristics of the study population}

Of the 500 NSCLC patients, 350 were male and 150 were female, and 331 patients were diagnosed with adenocarcinoma (ADC), while 169 had squamous-cell carcinomas (SCC). In addition, 280 male and 21 female patients were current or former smokers. There were 500 age-matched healthy controls (259 male and 240 female, and one subject did not have gender information). In the control group, 189 male and 14 female control subjects were current or former smokers. All subjects included in this study were of Chinese Han origin.

For all of the LRP6 SNPs (rs10845498, rs2075241, rs6488507, and rs7136900), cases and controls were within HWE ( $p=0.87,0.29,0.30$ and 0.26 for the cases; $\mathrm{p}=0.31,0.47,0.75$ and 0.67 for controls, respectively).

\section{LRP6 polymorphisms between case and control}

The allele frequency of $L R P 6$ rs 10845498 was $80.2 \%(\mathrm{~A})$ and $19.8 \%(\mathrm{G})$ in NSCLC patients, $81.0 \%$ (A) and $19.0 \%(\mathrm{G})$ in ADC patients, $78.7 \%(\mathrm{~A})$ and $21.3 \%$ (G) in SCC patients, and $82.8 \%(\mathrm{~A})$ and $17.2 \%(\mathrm{G})$ in controls. Allele frequency of LRP6 rs2075241 was 9.6\% (C) and $90.4 \%(\mathrm{G})$ in NSCLC patients, $10.7 \%(\mathrm{C})$ and $89.3 \%(\mathrm{G})$ in ADC patients, $12.4 \%(\mathrm{C})$ and $87.6 \%(\mathrm{G})$ in SCC patients, and $9.6 \%(C)$ and $90.4 \%(G)$ in controls. Allele frequency of LRP6 rs6488507 was $24.2 \%$ (A) and $75.8 \%(\mathrm{G})$ in NSCLC patients, $25.8 \%(\mathrm{~A})$ and $74.2 \%(\mathrm{G})$ in ADC patients, $26.0 \%(\mathrm{~A})$ and $74.0 \%(\mathrm{G})$ in SCC patients, and $25.9 \%(\mathrm{~A})$ and $74.1 \%(\mathrm{G})$ in controls. No statistical differences in allele frequencies of these four SNPs were found between the case and control subjects $(p>0.05)$. Stratification by gender revealed no significant difference in allele frequencies between male patients and male controls and between female patients and female controls (Table 2, 3, and 4).

LRP6 genotype distributions were also analyzed. Specifically, the frequency of the LRP6 rs10845498 genotype was $64.2 \%$ for $\mathrm{A} / \mathrm{A}, 32.0 \%$ for $\mathrm{A} / \mathrm{G}$, and $3.8 \%$ for $\mathrm{G} / \mathrm{G}$ in NSCLC patients, $69.2 \%$ for $\mathrm{A} / \mathrm{A}$, $27.2 \%$ for $A / G$, and $3.6 \%$ for $G / G$ in the controls. In contrast the frequency was $65.9 \%$ for $\mathrm{A} / \mathrm{A}, 30.2 \%$ for $A / G$, and $3.9 \%$ for $G / G$ in ADC patients and $60.9 \%$ for $A / A, 35.5 \%$ for $A / G$, and $3.6 \%$ for $G / G$ in SCC patients. There was no statistical difference of these four LRP6 SNP genotypes between NSLCLCs and controls, between ADC and controls, and between SCC and controls. After stratifying by gender, no statistical difference was observed. However, the LRP6 rs10845498 A/A major allele homozygote was associated with a decreased risk of lung SCC $(\mathrm{OR}=0.69$; 95\% CI, 0.48-1.00; Table 5).

Table 2. Allele frequency of LRP6 SNPs in NSCLC patients and healthy controls.

\begin{tabular}{|c|c|c|c|c|c|c|c|c|c|c|c|c|}
\hline \multirow[t]{2}{*}{ Gene allele } & \multicolumn{2}{|c|}{ NSCLC Controls } & \multirow{2}{*}{$\begin{array}{l}\mathrm{p} \\
\text { value }\end{array}$} & \multirow{2}{*}{ OR(95\% CI) } & \multirow{2}{*}{$\begin{array}{l}\text { M NSCLC } \\
\mathrm{N}=350(\%)\end{array}$} & \multirow{2}{*}{$\begin{array}{l}\text { M Controls } \\
\mathrm{N}=259(\%)\end{array}$} & \multirow{2}{*}{$\begin{array}{l}\mathrm{p} \\
\text { value }\end{array}$} & \multirow[t]{2}{*}{ OR $(95 \%$ CI $)$} & \multirow{2}{*}{$\begin{array}{l}\text { F NSCLC } \\
\mathrm{N}=150(\%)\end{array}$} & \multirow{2}{*}{$\begin{array}{l}\text { F Controls } \\
\mathrm{N}=240(\%)\end{array}$} & \multirow{2}{*}{$\begin{array}{l}\mathrm{p} \\
\text { value }\end{array}$} & \multirow{2}{*}{ OR(95\% CI) } \\
\hline & $\mathrm{N}=500(\%)$ & $\mathrm{N}=500(\%)$ & & & & & & & & & & \\
\hline \multicolumn{13}{|l|}{ Rs10845498 } \\
\hline A & $802(80.2)$ & $828(82.8)$ & & & 559 (79.9) & $424(81.9)$ & & & $243(81.0)$ & $403(84.0)$ & & \\
\hline G & $198(19.8)$ & $172(17.2)$ & 0.13 & $0.84(0.67-1.06)$ & $141(20.1)$ & $94(18.1)$ & 0.38 & $0.88(0.66-1.18)$ & $57(19.0)$ & 77 (16.0) & 0.29 & $0.81(0.55-1.19)$ \\
\hline \multicolumn{13}{|l|}{ Rs2075241 } \\
\hline $\mathrm{C}$ & $96(9.6)$ & $113(11.3)$ & & & 80 (11.4) & $57(11.0)$ & & & $33(11.0)$ & $39(8.1)$ & & \\
\hline G & $904(90.4)$ & $887(88.7)$ & 0.21 & $1.20(0.90-1.60)$ & $620(88.6)$ & $461(89.0)$ & 0.82 & $1.04(0.73-1.50)$ & $267(89.0)$ & 441 (91.9) & 0.19 & $1.39(0.84-2.28)$ \\
\hline \multicolumn{13}{|l|}{ Rs 6488507} \\
\hline A & $242(24.2)$ & 259 (25.9) & & & $184(26.3)$ & $129(24.9)$ & & & $75(25.0)$ & $111(23.1)$ & & \\
\hline G & $758(75.8)$ & $741(74.1)$ & 0.38 & 1.09 (0.89-1.34) & $516(73.7)$ & $389(75.1)$ & 0.58 & $1.08(0.83-1.39)$ & $225(75.0)$ & 369 (76.9) & 0.55 & $1.11(0.79-1.55)$ \\
\hline \multicolumn{13}{|l|}{ Rs7136900 } \\
\hline A & $69(6.9)$ & $81(8.1)$ & & & $51(7.3)$ & $35(6.8)$ & & & $18(6.0)$ & $45(9.4)$ & & \\
\hline G & 931 (93.1) & 919 (91.9) & 0.31 & $0.84(0.60-1.17)$ & 649 (92.7) & $483(93.2)$ & 0.72 & $1.08(0.69-1.69)$ & $282(94.0)$ & $435(90.6)$ & 0.09 & $0.62(0.35-1.09)$ \\
\hline
\end{tabular}

NSCLC, Non-small cell lung cancer; M, Male; F, Female. 
Table 3. Allele frequency of LRP6 SNPs in ADC patients and controls.

\begin{tabular}{|c|c|c|c|c|c|c|c|c|c|c|c|c|}
\hline Gene allele & $\mathrm{ADC}$ & Controls & $\begin{array}{l}\mathrm{p} \\
\text { value }\end{array}$ & OR (95\% CI) & M ADC & $\begin{array}{l}\text { M Con- } \\
\text { trols }\end{array}$ & $\begin{array}{l}\mathrm{p} \\
\text { value }\end{array}$ & $\begin{array}{l}\text { OR } \\
(95 \% \mathrm{CI})\end{array}$ & F ADC & F Controls & $\begin{array}{l}\mathrm{p} \\
\text { value }\end{array}$ & $\mathrm{OR}(95 \% \mathrm{CI})$ \\
\hline & $\mathrm{N}=331(\%)$ & $\mathrm{N}=500(\%)$ & & & $\mathrm{N}=189(\%)$ & $\mathrm{N}=259(\%)$ & & & $\begin{array}{l}\mathrm{N}=142 \\
(\%)\end{array}$ & $\mathrm{N}=240(\%)$ & & \\
\hline \multicolumn{13}{|l|}{ Rs10845498 } \\
\hline A & $536(81.0)$ & $828(82.8)$ & & & $306(81.0)$ & $424(81.9)$ & & & $230(81.0)$ & $403(84.0)$ & & \\
\hline G & $126(19.0)$ & $172(17.2)$ & 0.34 & $0.88(0.69-1.14)$ & $72(19.0)$ & $94(18.1)$ & 0.38 & $0.88(0.66-1.18)$ & $54(19.0)$ & $77(16.0)$ & 0.29 & $0.81(0.55-1.19)$ \\
\hline \multicolumn{13}{|l|}{ Rs2075241 } \\
\hline $\mathrm{C}$ & $71(10.7)$ & $96(9.6)$ & & & $40(10.6)$ & $57(11.0)$ & & & 31 (10.9) & $39(8.1)$ & & \\
\hline G & $591(89.3)$ & $904(90.4)$ & 0.46 & $1.13(0.82-1.56)$ & $338(89.4)$ & $461(89.0)$ & 0.84 & $0.96(0.62-1.47)$ & $253(89.1)$ & 441 (91.9) & 0.19 & $1.39(0.84-2.28)$ \\
\hline \multicolumn{13}{|l|}{ Rs 6488507} \\
\hline A & $171(25.8)$ & $242(24.2)$ & & & $99(26.2)$ & $129(24.9)$ & & & $72(25.4)$ & $111(23.1)$ & & \\
\hline G & $491(74.2)$ & $758(75.8)$ & 0.45 & 1.09 (0.87-1.37) & $279(73.8)$ & $389(75.1)$ & 0.66 & $1.07(0.79-1.45)$ & $212(74.6)$ & $369(76.9)$ & 0.49 & $1.13(0.80-1.59)$ \\
\hline \multicolumn{13}{|l|}{ Rs7136900 } \\
\hline A & $46(6.9)$ & $81(8.1)$ & & & $28(7.4)$ & $35(6.8)$ & & & $18(6.3)$ & $45(9.4)$ & & \\
\hline G & $616(93.1)$ & $919(91.9)$ & 0.39 & $0.85(0.58-1.23)$ & $350(92.6)$ & $483(93.2)$ & 0.71 & $1.10(0.66-1.85)$ & $266(93.7)$ & $435(90.6)$ & 0.14 & $0.65(0.37-1.15)$ \\
\hline
\end{tabular}

Table 4. Allele frequency of LRP6 SNPs in SCC patients and controls.

\begin{tabular}{|c|c|c|c|c|c|c|c|c|c|c|c|c|}
\hline Gene allele & SCC & Controls & $\begin{array}{l}\mathrm{p} \\
\text { value }\end{array}$ & $\begin{array}{l}\text { OR } \\
(95 \% \mathrm{CI})\end{array}$ & M SCC & M Controls & $\begin{array}{l}\mathrm{p} \\
\text { value }\end{array}$ & $\begin{array}{l}\text { OR } \\
(95 \% \mathrm{CI})\end{array}$ & F SCC & F Controls & $\begin{array}{l}\mathrm{p} \\
\text { value }\end{array}$ & $\begin{array}{l}\text { OR } \\
(95 \% \mathrm{CI})\end{array}$ \\
\hline & $\begin{array}{l}\mathrm{N}=169 \\
(\%)\end{array}$ & $\mathrm{N}=500(\%)$ & & & $\begin{array}{l}\mathrm{N}=161 \\
(\%)\end{array}$ & $\mathrm{N}=259(\%)$ & & & $\mathrm{N}=8(\%)$ & $\mathrm{N}=240(\%)$ & & \\
\hline \multicolumn{13}{|l|}{ Rs10845498 } \\
\hline A & $266(78.7)$ & $828(82.8)$ & & & 253 (78.6) & $424(81.9)$ & & & $13(81.3)$ & $403(84.0)$ & & \\
\hline G & $72(21.3)$ & $172(17.2)$ & 0.09 & $0.77(0.56-1.04)$ & $69(21.4)$ & 94 (18.1) & 0.24 & $0.81(0.57-1.15)$ & $3(18.7)$ & $77(16.0)$ & 0.77 & $0.83(0.23-2.97)$ \\
\hline \multicolumn{13}{|l|}{ Rs2075241 } \\
\hline $\mathrm{C}$ & $42(12.4)$ & $96(9.6)$ & & & $40(12.4)$ & 57 (11.0) & & & $2(12.5)$ & $39(8.1)$ & & \\
\hline G & $296(87.6)$ & 904 (90.4) & 0.14 & $1.33(0.91-1.97)$ & $282(87.6)$ & $461(89.0)$ & 0.53 & $1.15(0.75-1.77)$ & $14(87.5)$ & 441 (91.9) & 0.53 & $1.62(0.35-7.37)$ \\
\hline \multicolumn{13}{|l|}{ Rs 6488507} \\
\hline A & $88(26.0)$ & $242(24.2)$ & & & $85(26.4)$ & 129 (24.9) & & & $3(18.8)$ & $111(23.1)$ & & \\
\hline G & $250(74.0)$ & 758 (75.8) & 0.50 & $1.10(0.83-1.46)$ & $237(73.6)$ & $389(75.1)$ & 0.63 & $1.08(0.79-1.49)$ & 13 (81.3) & 369 (76.9) & 0.68 & $0.77(0.22-2.74)$ \\
\hline \multicolumn{13}{|l|}{ Rs7136900 } \\
\hline A & $23(6.8)$ & $81(8.1)$ & & & $23(7.1)$ & $35(6.8)$ & & & $0(0.0)$ & $45(9.4)$ & & \\
\hline G & 315 (93.2) & 919 (91.9) & 0.44 & $0.83(0.51-1.34)$ & 299 (92.9) & 483 (93.2) & 0.83 & $1.06(0.62-1.83)$ & $16(1.0)$ & 435 (90.6) & 0.20 & - \\
\hline
\end{tabular}

Table 5. Genotypes of LRP6 SNPs in SCC patients and controls.

\begin{tabular}{|c|c|c|c|c|c|c|c|c|c|c|c|c|}
\hline Gene allele & SCC & Controls & $\begin{array}{l}\mathrm{p} \\
\text { value }\end{array}$ & OR(95\% CI) & M SCC & $\begin{array}{l}\text { M Con- } \\
\text { trols }\end{array}$ & $\begin{array}{l}\mathrm{p} \\
\text { value }\end{array}$ & OR $(95 \%$ CI $)$ & F SCC & F Controls & $\begin{array}{l}\mathrm{p} \\
\text { value }\end{array}$ & OR(95\% CI) \\
\hline & $\mathrm{N}=169(\%)$ & $\mathrm{N}=500(\%)$ & & & $\mathrm{N}=161 \mathrm{n}(\%)$ & $\mathrm{N}=259(\%)$ & & & $\mathrm{N}=8(\%)$ & $\mathrm{N}=240(\%)$ & & \\
\hline \multicolumn{13}{|l|}{ Rs10845498 } \\
\hline AA & $103(60.9)$ & 346 (69.2) & & & $97(60.2)$ & 178 (68.7) & & & $6(75.0)$ & $168(70.0)$ & & \\
\hline AG & $60(35.5)$ & $136(27.2)$ & & & 59 (36.6) & $68(26.3)$ & & & $1(12.5)$ & $67(27.9)$ & & \\
\hline GG & $6(3.6)$ & $18(3.6)$ & 0.12 & & $5(3.1)$ & $13(5.0)$ & 0.06 & & $1(12.5)$ & $5(2.1)$ & 0.12 & \\
\hline $\mathrm{AG}+\mathrm{GG}$ & $66(39.1)$ & $154(30.8)$ & 0.04 & $0.69(0.48-1.00)$ & $64(39.8)$ & 81 (31.3) & 0.08 & $0.69(0.46-1.04)$ & $2(25.0)$ & $72(30.0)$ & 0.76 & $1.29(0.25-6.52)$ \\
\hline \multicolumn{13}{|l|}{ Rs2075241 } \\
\hline GG & 127 (751) & $410(82.0)$ & & & $121(75.2)$ & 205 (79.2) & & & $6(75.0)$ & $204(85.0)$ & & \\
\hline CG & 42 (249) & $84(16.8)$ & & & $40(24.8)$ & 51 (19.7) & & & $2(25.0)$ & $33(13.8)$ & & \\
\hline $\mathrm{CC}$ & $0(0.0)$ & $6(1.2)$ & 0.03 & & $0(0.0)$ & $3(1.2)$ & 0.19 & & $0(0.0)$ & $3(1.3)$ & 0.64 & \\
\hline $\mathrm{CC}+\mathrm{CG}$ & $42(24.9)$ & $90(18.0)$ & 0.05 & $0.66(0.44-1.01)$ & $40(24.8)$ & $54(20.8)$ & 0.34 & $0.80(0.50-1.27)$ & $2(25.0)$ & $36(15.0)$ & 0.44 & $0.53(0.10-2.73)$ \\
\hline \multicolumn{13}{|l|}{ Rs6488507 } \\
\hline GG & $92(54.4)$ & $286(57.2)$ & & & $86(53.4)$ & 148 (57.1) & & & $6(75.0)$ & $138(57.5)$ & & \\
\hline AG & $66(39.1)$ & $186(37.2)$ & & & $65(40.4)$ & 93 (35.9) & & & $1(12.5)$ & $9(3.7)$ & & \\
\hline AA & $11(6.5)$ & $28(5.6)$ & 0.79 & & $10(6.2)$ & $18(6.9)$ & 0.65 & & $1(12.5)$ & $93(38.8)$ & 0.19 & \\
\hline $\mathrm{AA}+\mathrm{AG}$ & $77(45.6)$ & $214(42.8)$ & 0.53 & $1.12(0.79-1.59)$ & 75 (46.6) & 111 (42.9) & 0.45 & $1.16(0.78-1.73)$ & $2(25.0)$ & $102(42.5)$ & 0.32 & $0.45(0.09-2.28)$ \\
\hline \multicolumn{13}{|l|}{ Rs7136900 } \\
\hline GG & $147(87.0)$ & $423(84.6)$ & & & 139 (86.3) & $226(87.3)$ & & & $8(1.0)$ & $197(82.1)$ & & \\
\hline AG & $21(12.4)$ & 73 (14.6) & & & $21(13.0)$ & 31 (12.0) & & & $0(0.0)$ & 41 (17.1) & & \\
\hline AA & $1(0.6)$ & $4(0.8)$ & 0.75 & & $1(0.6)$ & $2(0.8)$ & 0.94 & & $0(0.0)$ & $2(0.8)$ & 0.42 & \\
\hline $\mathrm{AG}+\mathrm{AA}$ & $22(13.0)$ & 77 (15.4) & 0.45 & $0.82(0.49-1.37)$ & $22(13.7)$ & 33 (12.7) & 0.78 & $1.08(0.61-1.94)$ & $0(0.0)$ & 43 (17.9) & 0.19 & - \\
\hline
\end{tabular}

SCC, squamous cell carcinoma; M, Male; F, Female. 


\section{Association between tobacco smoke and NSCLC}

We also analyzed the association of tobacco smoke with NSCLC risk. Logistic regression analysis showed that tobacco smokers had a 2.21-fold greater risk in developing NSCLC than nonsmokers $(p<0.01$, $95 \% \mathrm{CI}, 1.72-2.85)$. Moreover, we found that the LRP6 rs6488507 polymorphism synergistically increased the risk of NSCLC in tobacco smokers. For example, tobacco smokers who carried an "A" allele (AA+AG) had a 2.34-fold greater risk in developing NSCLC than other patients $(p<0.01,95 \% \mathrm{CI}, 1.74-3.13)$.

\section{Discussion}

In the current study, we investigated the association between LRP6 SNPs and the risk of developing NSCLC. Indeed, we found that the LRP6 rs10845498 polymorphism was associated with a reduced risk of lung SCC and that the LRP6 rs6488507 polymorphism synergistically increased the risk of NSCLC in tobacco smokers. To the best of our knowledge, this is the first report to demonstrate an association of the LRP6 rs10845498 SNP with NSCLC risk. However, further investigation is needed to elucidate mechanistic links between theLRP6 rs10845498 SNP, changes in LRP6 protein expression and activity, and lung cancer development and progression.

LRP6 is localized on chromosome 12p13.2, which is frequently deleted in NSCLC tissues [22-23]. The imbalance of chromosomal $12 p$ is also associated with disease progression [24]. In addition, chromosomal $12 p$ gain-of-function is also closely associated with tumorigenesis and/or the progression of lung SCC [25]. LRP6 is an essential co-receptor for Wnt/ $\beta$-catenin signaling [26-27] and plays a role in multiple processes involved in lung cancer development [28]. One study demonstrated a novel lung metastasis signature linked to Wnt signaling in basal-like breast cancer. Inhibition of Wnt signaling via LRP6 reduced the capacity of cancer cells to self-renew and seed tumors in vivo [29]. In accordance with these studies, our study indicated LRP6 may a susceptibility gene involved in NSCLC development. In this study, the LRP6 rs10845498 polymorphism was inversely associated with the development of lung SCC in a Chinese population. A/A homozygote individuals had a 0.69-fold reduced risk in developing NSCLC compared to $\mathrm{G} / \mathrm{G}$ homozygote or A/G heterozygote individuals. In addition we found that tobacco smokers had a 2.21-fold greater risk in developing NSCLC, while the LRP6 rs6488507 polymorphism synergistically increased the risk of lung cancer risk in tobacco smokers. Interestingly, the LRP6 rs6488507 polymorphism itself was not associated with the risk of de- veloping NSCLC. However, since the MAF of SNPs varies significantly between populations, associations based on these SNPs will be particularly sensitive to ethnic variability. Indeed, analysis of the HapMap database revealed a significant variability in the MAF of the LRP6 rs10845498 SNP among different populations. Specifically, the MAF of the LRP6 rs10845498 SNP in European (0.18) and Asian (0.21) populations is low, while it is high in Sub-Saharan African (0.29). Thus, the findings of the current study may be limited to Chinese patients and possibly other Asian populations. Indeed, further investigation is needed to confirm the applicability of our findings to other patient populations.

In the current study, the LRP6 rs10845498 polymorphism was associated with NSCLC risk, as well as synergistically affected NSCLC risk in tobacco smokers. However, our current study has some limitations. For example, we did not obtain clinicopathological data from the patients. In addition, our sample size was relatively small, which may have affected the result. In addition, population stratification may have led to a bias because the frequency of genotypes for many polymorphic variants differs markedly among different ethnic groups.

\section{Competing Interests}

The authors have declared that no competing interest exists.

\section{References}

1. Jemal A, Bray F, Center MM, et al. Global cancer statistics. CA Cancer J Clin. 2011;61:69-90.

2. Jie He, Wanqing Chen. Chinese cancer registry annual report (2012). Beijin, China: Military medicine society press; 2012.

3. [Internet] Howlader N, Noone AM, Krapcho M, et al. SEER Cancer Statistics Review, 1975-2010, National Cancer Institute. Bethesda, MD, http://seer.cancer.gov/csr/ 1975_2010/.

4. Matakidou A, Eisen T, Houlston RS. Systematic review of the relationship between family history and lung cancer risk. Br J Cancer. 2005;93:825-33.

5. Nusse $\mathrm{R}$, Theunissen $\mathrm{H}$, Wagenaar $\mathrm{E}$, et al. The Wnt-1 (int-1) oncogene promoter and its mechanism of activation by insertion of proviral DNA of the mouse mammary tumor virus. Mol Cell Biol. 1990;10:4170-9.

6. McMahon AP, Moon RT. Wnt-1-a proto-oncogene involved in cell signalling. Development. 1989;107 Suppl:161-7.

7. Van Ooyen A, Kwee V, Nusse R. The nucleotide sequence of the human int-1 mammary oncogene; evolutionary conservation of coding and non-coding sequences. EMBO J. 1985:4.2905-9.

8. Thomas KR, Capecchi MR. Targeted disruption of the murine int-1 proto-oncogene resulting in severe abnormalities in midbrain and cerebellar development. Nature. 1990;346:847-50.

9. Lee S, Kang J, Cho M, et al. Profiling of transcripts and proteins modulated by $\mathrm{K}$-ras oncogene in the lung tissues of K-ras transgenic mice by omics approaches. Int J Oncol. 2009;34:161-72.

10. Pacheco-Pinedo EC, Durham AC, Stewart KM, et al. Wnt/beta-catenin signaling accelerates mouse lung tumorigenesis by imposing an embryonic distal progenitor phenotype on lung epithelium. J Clin Invest. 2011;121:1935-45.

11. Gunther EJ, Moody SE, Belka GK, et al. Impact of p53 loss on reversal and recurrence of conditional Wnt-induced tumorigenesis. Genes Dev. 2003;17:488-501

12. MacDonald BT, Tamai $\mathrm{K}, \mathrm{He} \mathrm{X}$. Wnt/beta-catenin signaling: components, mechanisms, and diseases. Dev Cell. 2009:17:9-26.

13. He X, Semenov M, Tamai $K$, et al. LDL receptor-related proteins 5 and 6 in Wnt/beta-catenin signaling: arrows point the way. Development. 2004;131:1663-77

14. Liu CC, Pearson C, Bu G. Cooperative folding and ligand-binding properties of LRP6 beta-propeller domains. J Biol Chem. 2009;284:15299-307. 
15. Beachy PA, Karhadkar SS, Berman DM. Tissue repair and stem cell renewal in carcinogenesis. Nature. 2004;432:324-31.

16. Zeng $X$, Huang $H$, Tamai $K$, et al. Initiation of Wnt signaling: control of Wnt coreceptor Lrp6 phosphorylation/activation via frizzled, dishevelled and axin functions. Development. 2008;135:367-75.

17. Li Y, Lu W, He X, et al. LRP6 expression promotes cancer cell proliferation and tumorigenesis by altering beta-catenin subcellular distribution. Oncogene. 2004;23: 9129-35.

18. Lee JS, Hur MW, Lee SK, et al. A Novel sLRP6E1E2 Inhibits Canonical Wnt Signaling Epithelial-to-Mesenchymal Transition, and Induces MitochondriaDependent Apoptosis in Lung Cancer. PLoS One. 2012;7:e36520.

19. Na. LRP6 as a Candidate Oncogene that Regulates Tumor Proliferation. Cancer Biology \& Therapy. 2004;3:1192-9.

20. Pesch B, Kendzia B, Gustavsson P, et al. Cigarette smoking and lung cancer--relative risk estimates for the major histological types from a pooled analysis of case-control studies. Int J Cancer. 2012;131:1210-9.

21. Frusch N, Bosquée L, Louis R. Lung cancer, Epidemiology and etiologic factor. Rev Med Liege. 2007;62:548-53.

22. Grepmeier U, Dietmaier W, Merk J, et al. Deletions at chromosome $2 q$ and $12 p$ are early and frequent molecular alterations in bronchial epithelium and NSCLC of long-term smokers. Int J Oncol. 2005;27:481-8.

23. Berrieman HK, Ashman JN, Cowen ME, et al. Chromosomal analysis of non-small-cell lung cancer by multicolour fluorescent in situ hybridisation. $\mathrm{Br}$ J Cancer. 2004;90: 900-5.

24. Yakut T, Schulten HJ, Demir A, et al. Assessment of molecular events in squamous and non-squamous cell lung carcinoma. Lung Cancer. 2006;54:293-301.

25. Yan WS, Song LY, Wei WD, et al. Chromosomal imbalance in primary lung squamous cell carcinoma and their relationship with smoking. Ai Zheng. 2005;24:47-52.

26. Mi K, Johnson GV. Role of the intracellular domains of LRP5 and LRP6 in activating the Wnt canonical pathway. J Cell Biochem. 2005;95:328-38.

27. Xu Y, Gong W, Peng J, et al. Functional Analysis LRP6 Novel Mutations in Patients with Coronary Artery Disease. PLoS One. 2014;9:e84345.

28. Stewart DJ. Wnt signaling pathway in non-small cell lung cancer. Natl Cancer Inst. 2014;106:djt356.

29. DiMeo TA, Anderson K, Phadke P, et al. A novel lung metastasis signature links Wnt signaling with cancer cell self-renewal and epithelial-mesenchymal transition in basal-like breast cancer. Cancer Res. 2009;69: 5364-73. 